\author{
V.B. Vasilyev \\ Belgorod National Research University, Russia \\ (E-mail:vbv57@inbox.ru)
}

\title{
On some approximate calculations for certain pseudo-differential equations
}

\begin{abstract}
We consider discrete pseudo-differential operatots and equations as approximate operators and equations for their continuous analogues. For this purpose we study a solvability for such equations in appropriate discrete spaces and give some error estimates for discrete and continuous solutions. This approach is based on the discrete Fourier transform and factorization tecnique which is used for special canonical domains in Euclidean space.
\end{abstract}

Keywords: discrete pseudo-differential operator, periodic factorization, solvability, approximate solution, error estimates

\subsection{Introduction}

A theory of pseudo-differential operators and equations is a very developed part of mathematics now [1-3]. But almost there are results on an approximate solution for such equations and related boundary value problems. Therefore one suggests to start a studying pseudo-differential equations and boundary value problems on discrete structures for which is very convenient to construct computational algorithms. Here we will study model operators and equations in special canonical domains. We are interested in a solvability of discrete equations and a comparison of discrete and continue solutions.

Let $A(\xi)$ be a function defined in $\mathbb{R}^{m}$ and satisfying the condition

$$
c_{1}(1+|\xi|)^{\alpha} \leq|A(\xi)| \leq c_{2}(1+|\xi|)^{\alpha},
$$

with positive constants $c_{1}, c_{2}$, and let $S\left(\mathbb{R}^{m}\right)$ be the Schwartz space of infinitely differentiable rapidly decreasing at infinity functions. Such a function $A(\xi)$ generates a pseudo-differential operator

$$
(A u)(x)=\int_{\mathbb{R}^{m}} \int_{\mathbb{R}^{m}} A(\xi) e^{i(x-y) \cdot \xi} u(y) d \xi d y, \quad x \in \mathbb{R}^{m},
$$

which is defined firstly for $u \in S\left(\mathbb{R}^{m}\right)$, and then it will extend on more general spaces. This function $A(\xi)$ is called a symbol of pseudo-differential operator $A$.

Remark 1. Usually they consider more general pseudo-differential operators

$$
(A u)(x)=\int_{\mathbb{R}^{m}} \int_{\mathbb{R}^{m}} A(x, \xi) e^{i(x-y) \cdot \xi} u(y) d \xi d y, \quad x \in \mathbb{R}^{m},
$$

generated by the symbol $A(x, \xi)$ defined in $\mathbb{R}^{m} \times \mathbb{R}^{m}$. But taking into account so-called «a local principle» our nearest problem is studying more simple operator (2) and its discrete analogue.

Let $A_{d}(\xi)$ be a periodic function in $\mathbb{R}^{m}$ so that

$$
c_{1}\left(1+\left|\zeta_{h}^{2}\right|\right)^{\frac{\alpha}{2}} \leq\left|A_{d}(\xi)\right| \leq c_{2}\left(1+\left|\zeta_{h}^{2}\right|\right)^{\frac{\alpha}{2}},
$$

where $\zeta_{h}^{2}=h^{-2} \sum_{k=1}^{m}\left(e^{-i h \xi_{k}}-1\right)^{2}$, and positive constants $c_{1}, c_{2}$ do not depend on $h$.

Let $D \subset \mathbb{R}^{m}$ be a domain (finite or infinite). We will consider functions $u_{d}(\tilde{x})$ defined in $D_{d} \equiv D \cap h \mathbb{Z}^{m}, h>0$, and introduce the following operator

$$
\left(A_{d} u_{d}\right)(\tilde{x})=\sum_{\tilde{y} \in h \mathbb{Z}^{m}} \int_{\hbar \mathbb{T}^{m}} A_{d}(\xi) u_{d}(\tilde{y}) e^{i(\tilde{x}-\tilde{y}) \cdot \xi} h^{m} d \xi, \quad \tilde{x} \in D_{d}
$$

where $\hbar \equiv h^{-1}, \mathbb{T}^{m} \equiv[-\pi, \pi]^{m}$. 
Definition 1. The operator $A_{d}$ is called a discrete pseudo-differential operator or shortly h-operator. The periodic function $A_{d}(\xi)$ is called its $\hbar$-symbol.

Let us remind that a symbol (operator) is called elliptic if

$$
\text { ess } \inf _{\xi \in \hbar \mathbb{R}^{m}}\left|A_{d}(\xi)\right|>0
$$

and obviously all symbols under consideration are elliptic.

\subsubsection{The discrete Fourier transform}

If $u_{d}(\tilde{x}), \tilde{x} \in h \mathbb{Z}^{m}$ is a function of a discrete variable then we say «discrete function». For such discrete functions one can define the discrete Fourier transform

$$
\left(F_{d} u_{d}\right)(\xi) \equiv \tilde{u}_{d}(\xi)=\sum_{\tilde{x} \in h \mathbb{Z}^{m}} e^{-i \tilde{x} \cdot \xi} u_{d}(\tilde{x}) h^{m}, \quad \xi \in \hbar \mathbb{T}^{m},
$$

if the latter series converges. The obtained function $\tilde{u}_{d}(\xi)$ is periodic in $\mathbb{R}^{m}$ with basic cube of periods $\hbar \mathbb{T}^{m}$. Such discrete Fourier transform preserves all key properties of the integral Fourier transform, particularly the inverse discrete Fourier transform is given by the formula

$$
\left(F_{d}^{-1} \tilde{u}_{d}\right)(\tilde{x})=\frac{1}{(2 \pi)^{m}} \int_{\hbar \mathbb{T}^{m}} e^{i \tilde{x} \cdot \xi} \tilde{u}_{d}(\xi) d \xi, \quad \tilde{x} \in h \mathbb{Z}^{m} .
$$

The discrete Fourier transform is an isomorphism between the spaces $L_{2}\left(h \mathbb{Z}^{m}\right)$ and $L_{2}\left(\hbar \mathbb{T}^{m}\right)$ with norms

$$
\left\|u_{d}\right\|_{2}=\left(\sum_{\tilde{x} \in h \mathbb{Z}^{m}}\left|u_{d}(\tilde{x})\right|^{2} h^{m}\right)^{1 / 2} \text { and }\left\|\tilde{u}_{d}\right\|_{2}=\left(\int_{\xi \in \hbar \mathbb{T}^{m}}\left|\tilde{u}_{d}(\xi)\right|^{2} d \xi\right)^{1 / 2} .
$$

\subsubsection{Discrete spaces}

Since a definition of Sobolev-Slobodetskii spaces uses patrial derivatives we will use their discrete analogues, namely divided differences of first order

$$
\left(\Delta_{k}^{(1)} u_{d}\right)(\tilde{x})=h^{-1}\left(u_{d}\left(x_{1}, \cdots, x_{k}+h, \cdots, x_{m}\right)-u_{d}\left(x_{1}, \cdots, x_{k}, \cdots, x_{m}\right)\right),
$$

for which their discrete Fourier transform looks as follows

$$
\left.\widetilde{\left(\Delta_{k}^{(1)} u_{d}\right.}\right)(\xi)=h^{-1}\left(e^{-i h \cdot \xi_{k}}-1\right) \tilde{u}_{d}(\xi) .
$$

For a divided difference of a second order we have obviously

$$
\begin{gathered}
\left(\Delta_{k}^{(2)} u_{d}\right)(\tilde{x})=h^{-2}\left(u_{d}\left(x_{1}, \cdots, x_{k}+2 h, \cdots, x_{m}\right) ;\right. \\
\left.-2 u_{d}\left(x_{1}, \cdots, x_{k}+h, \cdots, x_{m}\right)+u_{d}\left(x_{1}, \cdots, x_{k}, \cdots, x_{m}\right)\right),
\end{gathered}
$$

and its discrete Fourier transform is

$$
\left.\widetilde{\left(\Delta_{k}^{(2)} u_{d}\right.}\right)(\xi)=h^{-2}\left(e^{-i h \cdot \xi_{k}}-1\right)^{2} \tilde{u}_{d}(\xi)
$$

Then for the discrete Laplacian

$$
\left(\Delta_{d} u_{d}\right)(\tilde{x})=\sum_{k=1}^{m}\left(\Delta_{k}^{(2)} u_{d}\right)(\tilde{x})
$$

we have

$$
\left.\widetilde{\left(\Delta_{d} u_{d}\right.}\right)(\xi)=h^{-2} \sum_{k=1}^{m}\left(e^{-i h \cdot \xi_{k}}-1\right)^{2} \tilde{u}_{d}(\xi) .
$$


Further we introduce the space $S\left(h \mathbb{Z}^{m}\right)$ consisting of functions with finite semi-norms

$$
\left|u_{d}\right|=\sup _{\tilde{x} \in h \mathbb{Z}^{m}}(1+|\tilde{x}|)^{l}\left|\Delta^{(\mathbf{k})} u_{d}(\tilde{x})\right|
$$

for all $l \in \mathbb{N}, \mathbf{k}=\left(k_{1}, \cdots, k_{m}\right), k_{r} \in \mathbb{N}, r=1, \cdots, m$, where

$$
\Delta^{(\mathbf{k})} u_{d}(\tilde{x})=\Delta_{1}^{k_{1}} \ldots, \Delta_{m}^{k_{m}} u_{d}(\tilde{x}) .
$$

In other words the space $S\left(h \mathbb{Z}^{m}\right)$ is a discrete analogue of the Schwartz space $S\left(\mathbb{R}^{m}\right)$.

Definition 2. By definition the space $H^{s}\left(h \mathbb{Z}^{m}\right)$ is a closure of the space $S\left(h \mathbb{Z}^{m}\right)$ with respect to the norm

$$
\left\|u_{d}\right\|_{s}=\left(\int_{\hbar \mathbb{T}^{m}}\left(1+\left|\zeta_{h}^{2}\right|\right)^{s}\left|\tilde{u}_{d}(\xi)\right|^{2} d \xi\right)^{1 / 2} .
$$

Definition 3. The space $H^{s}\left(D_{d}\right)$ consists of discrete functions from $H^{s}\left(h \mathbb{Z}^{m}\right)$ with supports in $\overline{D_{d}}$. A norm in the space $H^{s}\left(D_{d}\right)$ is induced by a norm of the space $H^{s}\left(h \mathbb{Z}^{m}\right)$. The space $H_{0}^{s}\left(D_{d}\right)$ consists of discrete functions (distributions from $S^{\prime}\left(\mathbb{R}^{m}\right)$ ) $u_{d}$ with supports in $D_{d}$, additionally these discrete functions must admit a continuation $\ell$ onto $H^{s}\left(h \mathbb{Z}^{m}\right)$. A norm in the space $H_{0}^{s}\left(D_{d}\right)$ is given by the formula

$$
\left\|u_{d}\right\|_{s}^{+}=\inf \left\|\ell u_{d}\right\|_{s}
$$

where infimum is taken over all continuations $\ell$.

Of course all norms (4) are equivalent to $L_{2}$-norm, but all equivalence constants will depend on $h$. That is why we would like to note that all constants below do not depend on $h$.

\subsection{Equations and approximations}

We will consider the pseudo-differential equation

$$
(A u)(x)=v(x), \quad x \in D,
$$

and suggest for its solution some computational schemes.

Since we know solvability conditions for pseudo-differential equations in $\mathbb{R}^{m}$ and $\mathbb{R}_{+}^{m}[3]$ we will select such discrete pseudo-differential operators which reserve all needed properties of their continuous analogues.

Let $P_{h}$ be a restriction operator on $h \mathbb{Z}^{m}$, i. e. for $u \in S\left(\mathbb{R}^{m}\right)$

$$
\left(P_{h} u\right)(x)=\left\{\begin{array}{cl}
u(\tilde{x}), & x=\tilde{x} \in h \mathbb{Z}^{m} ; \\
0, & x \notin h \mathbb{Z}^{m} .
\end{array}\right.
$$

We tried this projector for simplest pseudo-differential operators, namely Calderon-Zygmund operators, these operators can be treated as pseudo-differential operators of order 0 , and we obtained very acceptable results [4-7]. But now we will use another restriction operator.

A construction for the restriction operator $Q_{h}$ for functions $u \in S\left(\mathbb{R}^{m}\right)$ is the following. We take the Fourier transform $\tilde{u}(\xi)$, then its restriction on $\hbar \mathbb{T}^{m}$ and periodically continue it onto a whole $\mathbb{R}^{m}$. Further we apply the inverse discrete Fourier transform $F_{d}^{-1}$ and obtain a discrete function which is denoted by $\left(Q_{h} u\right)(\tilde{x}), \tilde{x} \in h \mathbb{Z}^{m}$. In our opinion the projector $Q_{h}$ is more convenient than $P_{h}$ although the projectors $P_{h}$ and $Q_{h}$ are almost the same according to the following result.

Lemma 1. For $u \in S\left(\mathbb{R}^{m}\right), \forall \beta>0$, we have

$$
\left|\left(P_{h} u\right)(\tilde{x})-\left(Q_{h} u\right)(\tilde{x})\right| \leq C h^{\beta}, \quad \forall \tilde{x} \in h \mathbb{Z}^{m},
$$

where the constant $C$ depends on $u$ only.

Proof. Indeed, we need to compare two Fourier transforms. By definition

$$
\left(P_{h} u\right)(\tilde{x})=\frac{1}{(2 \pi)^{m}} \int_{\mathbb{R}^{m}} e^{i \tilde{x} \cdot \xi} \tilde{u}(\xi) d \xi,
$$


and respectively

$$
\left(Q_{h} u\right)(\tilde{x})=\frac{1}{(2 \pi)^{m}} \int_{\hbar \mathbb{T}^{m}} e^{i \tilde{x} \cdot \xi} \tilde{u}(\xi) d \xi
$$

thus this difference is given by the integral

$$
\left(P_{h} u\right)(\tilde{x})-\left(Q_{h} u\right)(\tilde{x})=\frac{1}{(2 \pi)^{m}} \int_{\mathbb{R}^{m} \backslash \hbar \mathbb{T}^{m}} e^{i \tilde{x} \cdot \xi} \tilde{u}(\xi) d \xi .
$$

A conclusion of the lemma 1 follows from an invariance of the Schwartz class $S\left(\mathbb{R}^{m}\right)$ with respect to the Fourier transform and the simple estimate

$$
|\tilde{u}(\xi)| \leq C_{u}|\xi|^{-\gamma}
$$

for $\forall \gamma>0$.

Further, the symbol $A_{d}(\xi)$ will be defined by the following way. We take a restriction of $A(\xi)$ on the cube $\hbar \mathbb{T}^{m}$ and periodically extend it onto a whole $\mathbb{R}^{m}$. We consider such $h$-operator as an approximate operator for $A$. So, to find an approximate discrete solution for the equation

$$
\left(A_{d} u_{d}\right)(\tilde{x})=v_{d}(\tilde{x}), \quad \tilde{x} \in D_{d},
$$

for $D=\mathbb{R}^{m}$ we can use the following discrete equation

$$
A_{d} u_{d}=Q_{h} v
$$

Its solution is given by the formula

$$
u_{d}(\tilde{x})=\frac{1}{(2 \pi)^{m}} \int_{\hbar \mathbb{T}^{m}} e^{i \tilde{x} \cdot \xi} A^{-1}(\xi) \tilde{v}(\xi) d \xi, \quad \tilde{x} \in h \mathbb{Z}^{m},
$$

so that we do not need to find an approximate solution for an infinite system of linear algebraic equations like $[4,5]$. For our case we need to apply any kind of cubature formulas for calculating the latter integral and a cubature formula for calculating the Fourier transform $\tilde{v}(\xi)$.

According to the Lemma 1 one can compare discrete and continuous solutions for enough smooth right-hand sides and symbols.

Theorem 1. If the symbol $A(\xi)$ satisfies the condition (1) and is infinitely differentiable on $\mathbb{R}^{m}, u$ is a solution of the equation (5), $u_{d}$ is a solution of the equation (7) then for $v \in S\left(\mathbb{R}^{m}\right)$ we have the following error estimate

$$
\left|u(\tilde{x})-u_{d}(\tilde{x})\right| \leq C h^{\beta}, \quad \forall \tilde{x} \in h \mathbb{Z}^{m},
$$

for arbitrary $\beta>0$.

\subsection{Equations in a half-space}

This case is very different from $\mathbb{R}^{m}$, and an ellipticity condition is not sufficient for a solvability. A principal role for the solvability is plaid by an index of the periodic factorization which is defined for an elliptic symbol.

Let us denote $\Pi_{ \pm}=\left\{\left(\xi^{\prime}, \xi_{m} \pm i \tau\right), \tau>0\right\}, \xi=\left(\xi^{\prime}, \xi_{m}\right) \in \mathbb{T}^{m}$.

Definition 4. The periodic factorization for an elliptic symbol $A_{d}(\xi)$ is called its representation in the form

$$
A_{d}(\xi)=A_{d,+}(\xi) A_{d,-}(\xi),
$$

where the factors $A_{d, \pm}(\xi)$ admit an analytical continuation into half-strips $\hbar \Pi_{ \pm}$with respect to a last variable $\xi_{m}$ for almost all fixed $\xi^{\prime} \in \hbar \mathbb{T}^{m-1}$ and satisfy the estimates

$$
\left|A_{d,+}^{ \pm 1}(\xi)\right| \leq c_{1}\left(1+\left|\hat{\zeta}^{2}\right|\right)^{ \pm \frac{\infty}{2}}, \quad\left|A_{d,-}^{ \pm 1}(\xi)\right| \leq c_{2}\left(1+\left|\hat{\zeta}^{2}\right|\right)^{ \pm \frac{\alpha-\infty}{2}},
$$

with constants $c_{1}, c_{2}$ non-depending on $h$,

$$
\hat{\zeta}^{2} \equiv \hbar^{2}\left(\sum_{k=1}^{m-1}\left(e^{-i h \xi_{k}}-1\right)^{2}+\left(e^{-i h\left(\xi_{m}+i \tau\right)}-1\right)^{2}\right), \quad \xi_{m}+i \tau \in \hbar \Pi_{ \pm} .
$$


The number $æ \in \mathbb{R}$ is called an index of the periodic factorization.

Theorem 2. If the elliptic symbol $\tilde{A}_{d}(\xi)$ admits the periodic factorization with the index æ so that $|æ-s|<1 / 2$ then the equation (6) has a unique solution in the space $H^{s}\left(D_{d}\right)$ for arbitrary right-hand side $v_{d} \in H_{0}^{s-\alpha}\left(D_{d}\right)$,

$$
\begin{gathered}
\tilde{u}_{d}(\xi)=\tilde{A}_{d,+}^{-1}(\xi) P_{\xi^{\prime}}^{p e r}\left(\tilde{A}_{d,-}^{-1}(\xi) \widetilde{\ell v_{d}}(\xi)\right), \\
\left(P_{\xi^{\prime}}^{p e r} \tilde{u}_{d}\right)(\xi) \equiv \frac{1}{2}\left(\tilde{u}_{d}(\xi)+\frac{h}{2 \pi i} v \cdot p \cdot \int_{-\hbar \pi}^{\hbar \pi} \tilde{u}_{d}\left(\xi^{\prime}, \eta_{m}\right) \cot \frac{h\left(\xi_{m}-\eta_{m}\right)}{2} d \eta_{m}\right),
\end{gathered}
$$

Remark 2. One can easily conclude that the solution does not depend on a continuation $\ell v_{d}$.

Theorem 3. Let $æ-s=n+\delta, n \in \mathbb{N},|\delta|<1 / 2$. Then a general solution of the equation (6) in Fourier images has the following form

$$
\tilde{u}_{d}(\xi)=\tilde{A}_{d,+}^{-1}(\xi) X_{n}(\xi) P_{\xi^{\prime}}^{p e r}\left(X_{n}^{-1}(\xi) \tilde{A}_{d,-}^{-1}(\xi) \widetilde{\ell_{d}}(\xi)\right)+\tilde{A}_{d,+}^{-1}(\xi) \sum_{k=0}^{n-1} c_{k}\left(\xi^{\prime}\right) \hat{\zeta}_{m}^{k},
$$

where $X_{n}(\xi)$ is arbitrary polynomial of order $n$ of variables $\hat{\zeta}_{k}=\hbar\left(e^{-i h \xi_{k}}-1\right), k=1, \cdots, m$ satisfying the condition $(3), c_{j}\left(\xi^{\prime}\right), j=0,1, \cdots, n-1$, are arbitrary functions from $H_{s_{j}}\left(h \mathbb{T}^{m-1}\right), s_{j}=s-æ+j-1 / 2$.

For the case $æ-s=-n+\delta, n \in \mathbb{N},|\delta|<1 / 2$, we consider the following general equation

$$
\left(A_{d} u_{d}\right)(\tilde{x})+\sum_{j=0}^{n} K_{j}\left(\tilde{b}_{j}\left(\tilde{x}^{\prime}\right) \otimes \delta\left(\tilde{x}_{m}\right)\right)=v_{d}(\tilde{x}), \quad \tilde{x} \in D_{d}
$$

with unknowns $u_{d}, \tilde{b}_{j}, j=0,1, \cdots, n$, and $K_{j}$ are given pseudo-differential operators with symbols $K_{j}(\xi)$ satisfying the condition (3) with power $\alpha_{j}$.

Remark 3. The operator $K_{j}$ acts as follows. If we denote by $\hat{K}_{j}(\tilde{x})$ a kernel of the pseudo-differential operator $K_{j}$, we obtain

$$
K_{j}\left(\tilde{b}_{j}\left(\tilde{x}^{\prime}\right) \otimes \delta\left(\tilde{x}_{m}\right)\right)=\sum_{\tilde{y} \in h \mathbb{Z}^{m-1}} \hat{K}_{j}\left(\tilde{x}^{\prime}-\tilde{y}^{\prime}, \tilde{x}_{m}\right) b_{j}\left(\tilde{y}^{\prime}\right) h^{m-1} .
$$

Continuing the right-hand side onto a whole $\mathbb{R}^{m}$ and applying the discrete Fourier transform, we obtain the system of linear algebraic equations

$$
\sum_{j=0}^{n} t_{k j}\left(\xi^{\prime}\right) \tilde{b}_{j}\left(\xi^{\prime}\right)=f_{k}\left(\xi^{\prime}\right), \quad k=0,1, \cdots, n
$$

where

$$
\begin{gathered}
t_{k j}\left(\xi^{\prime}\right)=\frac{1}{2 \pi} \int_{-\hbar \pi}^{\hbar \pi}\left(\frac{e^{-i h \xi_{m}}-1}{h}\right)^{k} \frac{K_{j}\left(\xi^{\prime}, \xi_{m}\right)}{A_{d,-}\left(\xi^{\prime}, \xi_{m}\right)} d \xi_{m} ; \\
f_{k}\left(\xi^{\prime}\right)=\frac{1}{2 \pi} \int_{-\hbar \pi}^{\hbar \pi}\left(\frac{e^{-i h \xi_{m}}-1}{h}\right)^{k} A_{d,-}^{-1}\left(\xi^{\prime}, \xi_{m}\right) \widetilde{\left(\ell v_{d}\right)}\left(\xi^{\prime}, \xi_{m}\right) d \xi_{m} .
\end{gathered}
$$

Theorem 4. Let $æ-s=-n+\delta, n \in \mathbb{N},|\delta|<1 / 2$. Then the equation (9) has a unique solution $u_{d} \in$ $H^{s}\left(D_{d}\right), c_{j} \in H^{s_{j}}\left(h \mathbb{Z}^{m-1}\right), s_{j}=s-\alpha+\alpha_{j}+1 / 2, j=0,1, \cdots, n$, iff

$$
\text { ess } \inf _{\xi^{\prime} \in h \mathbb{T}^{m-1}} \mid \operatorname{det}\left(t_{k j}\left(\xi^{\prime}\right)\right)_{k, j=0}^{n}>0 \text {. }
$$

The following estimate

$$
\left\|u_{d}\right\|_{s} \leq a\left\|v_{d}\right\|_{s-\alpha}^{+}, \quad\left\|b_{j}\right\|_{s_{j}} \leq a_{j}\left\|v_{d}\right\|_{s-\alpha}^{+}, \quad j=0,1, \cdots, n,
$$

holds with constants $a, a_{1}, \cdots, a_{n}$, non-depending on $h$. 


\subsubsection{A limit case}

It is well-known [8] that

$$
\cot x=\frac{1}{x}-\sum_{n=1}^{\infty} \frac{2^{2 n}\left|B_{2 n}\right|}{(2 n) !} x^{2 n-1}, \quad-\pi<x<\pi,
$$

where $B_{2 n}$ are Bernoulli numbers.

In the formula (8) a kernel of the operator $P_{\xi^{\prime}}^{\text {per }}$, i. e. $h \cot \frac{h \xi_{m}}{2}$ has the following representation

$$
h \cot \frac{h \xi_{m}}{2}=\frac{2}{\xi_{m}}-h \sum_{n=1}^{\infty} \frac{2^{2 n}\left|B_{2 n}\right|}{(2 n) !}\left(\frac{h \xi_{m}}{2}\right)^{2 n-1},
$$

so that we will obtain under $h \rightarrow 0$ a well-known kernel of the Hilbert transform $\frac{1}{\pi i} \frac{1}{\xi_{m}}$ with respect to a last variable. Also it is easily visible that under $h \rightarrow 0$ all periodic polynomials in Theorem 2 transform to ordinary polynomials with respect to the variable $\xi_{m}$. It is very correlated with a continuous case [3].

Unfortunately, for this case the estimates for a comparison of $u$ and $u_{d}$ are not so simple as in the theorem 1 ; now we can assert that $\tilde{u}_{d}$ converges to $\tilde{u}$ under $h \rightarrow 0$.

\subsubsection{An error estimate}

If we put strong enough restrictions on a right-hand side and factorization elements then one can give a comparison between discrete and continuous solutions.

Lemma 2. If $u \in S\left(\mathbb{R}^{m}\right)$ then the following estimate

$$
\left|\left(F^{-1} P_{\xi^{\prime}} \tilde{u}\right)(\tilde{x})-\left(F_{d}^{-1} P_{\xi^{\prime}}^{\text {per }} \widetilde{Q_{h} u}\right)(\tilde{x})\right| \leq C h^{\beta}, \quad \tilde{x} \in h \mathbb{Z}_{+}^{m}
$$

holds for $\forall \beta>0$, and the constant $C$ depends on $u$ only.

Proof. Here we need the description and comparison for two projectors related to the Hilbert transform, both standard and periodic. Let us denote by $\chi(x)$ an indicator of the half-space $\mathbb{R}_{+}^{m}$ and by $\chi_{d}(\tilde{x})$ an indicator of the discrete half-space $h \mathbb{Z}_{+}^{m}$. Then according to structural properties of two mentioned transforms we have the following equalities

$$
F^{-1} P_{\xi^{\prime}} \tilde{u}=\chi \cdot u, \quad F_{d}^{-1} P_{\xi^{\prime}}^{p e r} \widetilde{Q_{h} u}=\chi_{d} \cdot\left(Q_{h} u\right) .
$$

Further one can apply Lemma 1.

Starting from Lemma 2 and the Theorem 1 we are able to compare discrete and continuous solutions in a half-space. Below we give this comparison under conditions of the Theorem 2 when a unique solution exists.

Theorem 5. If the symbol $A(\xi)$ satisfies the condition (1) and is infinitely differentiable in $\mathbb{R}^{m}$ with the factors $A_{ \pm}(\xi), u$ is a solution of the equation (5), $u_{d}$ is a solution of the equation (7) then for $v \in S\left(\mathbb{R}^{m}\right)$ we have the following error estimate

$$
\left|u(\tilde{x})-u_{d}(\tilde{x})\right| \leq C h^{\beta}, \quad \forall \tilde{x} \in h \mathbb{Z}_{+}^{m},
$$

for arbitrary $\beta>0$.

Remark 4. To refine this theorem we will describe how we need to choose a right-hand side for solving the equation (7). The solution of the equation (5) in Fourier images has the form

$$
\tilde{u}(\xi)=A_{+}^{-1}(\xi) P_{\xi^{\prime}} A_{-}^{-1}(\xi) \widetilde{\ell v}(\xi),
$$

where $P_{\xi^{\prime}}=\frac{1}{2}\left(I+H_{\xi^{\prime}}\right)$ is a projector defined by the classical Hilbert transform with respect to a variable $\xi_{m}$ [3]:

$$
\left(H_{\xi^{\prime}} \tilde{u}\right)(\xi)=\frac{1}{\pi i} v \cdot p \cdot \int_{-\infty}^{+\infty} \frac{\tilde{u}\left(\xi^{\prime}, \eta_{m}\right) d \eta_{m}}{\xi_{m}-\eta_{m}},
$$

$\ell v$ is an arbitrary continuation of $v$ from $\mathbb{R}_{+}^{m}$ onto a whole $\mathbb{R}^{m}$ in corresponding functional space. Since the right-hand side in the equation (6) is defined in $h \mathbb{Z}_{+}^{m}$ only then one needs to choose $Q_{h}(\ell v)$ instead of $\ell v_{d}$ to obtain the required estimate. 


\subsection{Equations in a cone}

Here we will consider briefly more complicated case than a half-space.

Let $D$ be a sharp convex cone, and let $\stackrel{*}{D}$ be a conjugate cone for $D$, i.e.,

$$
\stackrel{*}{D}=\left\{x \in \mathbb{R}^{m}: x \cdot y>0, y \in D\right\} .
$$

Let $T(\stackrel{*}{D}) \subset \mathbb{C}^{m}$ be a set of the type $\mathbb{T}^{m}+i \stackrel{*}{D}$. For $\mathbb{T}^{m} \equiv \mathbb{R}^{m}$ such a domain of multidimensional complex space is called a radial tube domain over the cone $\stackrel{*}{D}[9-11]$. We introduce the function

$$
B_{d}(z)=\sum_{\tilde{x} \in D_{d}} e^{i \tilde{x} \cdot z}, \quad z=\xi+i \tau, \quad \xi \in \mathbb{T}^{m}, \quad \tau \in \stackrel{*}{D},
$$

and define the operator

$$
\left(B_{d} u\right)(\xi)=\lim _{\tau \rightarrow 0} \int_{\mathbb{T}^{m}} B_{d}(z-\eta) u_{d}(\eta) d \eta
$$

This operator is roughly speaking a conical analogue of the periodic Hilbert transform $H_{\xi^{\prime}}^{\text {per }}$.

To describe solvability conditions for the equation (6) we introduce the following concept.

Definition 5. The periodic wave factorization for an elliptic symbol $A_{d}(\xi)$ is called its representation in the form

$$
A_{d}(\xi)=A_{d, \neq}(\xi) A_{d,=}(\xi)
$$

where the factors $A_{d, \neq}(\xi), A_{d,=}(\xi)$ admit an analytical continuation into domains $T(\stackrel{*}{D}), T(-\stackrel{*}{D})$ respectively and satisfy the estimates

$$
\left|A_{d, \neq}^{ \pm 1}(\xi)\right| \leq c_{1}\left(1+\left|\hat{\zeta}^{2}\right|\right)^{ \pm \frac{x}{2}}, \quad\left|A_{d,=}^{ \pm 1}(\xi)\right| \leq c_{2}\left(1+\left|\hat{\zeta}^{2}\right|\right)^{ \pm \frac{\alpha-\infty}{2}},
$$

with constants $c_{1}, c_{2}$ non-depending on $h$,

$$
\hat{\zeta}^{2} \equiv \hbar^{2}\left(\sum_{k=1}^{m}\left(e^{-i h\left(\xi_{k}+\tau_{k}\right)}-1\right)^{2}\right), \quad \xi \in \mathbb{T}^{m}, \tau \in \pm \stackrel{*}{D} .
$$

The number $æ \in \mathbb{R}$ is called an index of the periodic wave factorization.

Theorem 6. If the elliptic symbol $\tilde{A}_{d}(\xi)$ admits periodic wave factorization with the index $æ$ so that $|æ-s|<$ $1 / 2$ then the operator $A_{d}: H^{s}\left(D_{d}\right) \rightarrow H^{s-\alpha}\left(D_{d}\right)$ is invertible and a solution of the equation (6) for arbitrary right-hand side $v_{d} \in H_{0}^{s}\left(D_{d}\right)$ in Fourier images is given by the formula

$$
\tilde{u}_{d}(\xi)=A_{d, \neq}^{-1}(\xi) B_{d}\left(A_{d,=}^{-1}(\xi) \widetilde{\ell v_{d}}(\xi)\right),
$$

where $\ell v_{d}$ is an arbitrary continuation of $v_{d}$ into $H^{s}\left(h \mathbb{Z}^{m}\right)$.

Using the latter formula (10) for the solution of the equation (6) and the previous considerations one can obtain conical analogues of theorems 1 and 5 . We hope to give more detailed analysis in forthcoming papers.

\section{References}

1 Taylor, M.E. (1981). Pseudodifferential operators. Princeton, Princeton Univ. Press.

2 Treves, J.-F. (1980). Introduction to pseudodifferential and Fourier integral operators. New York: Springer.

3 Eskin, G. (1981). Boundary value problems for elliptic pseudodifferential equations. AMS, Providence.

4 Vasilyev, A.V., \& Vasilyev, V.B. (2013). Discrete singular operators and equations in a half-space. Azerb. J. Math., Vol.3, No. 1, 84-93.

5 Vasil'ev A.V., \& Vasil'ev V.B. (2015). On the solvability of certain discrete equations and related estimates of discrete operators. Doklady Math., Vol. 92, No. 2, 585-589.

6 Vasilyev, A.V., \& Vasilyev, V.B. (2015). Discrete singular integrals in a half-space. In: V.V. Mityushev, M.V. Ruzhansky (Eds.). Current Trends in Analysis and its Applications. Trends in Mathematics, Birkhäuser, Basel, p. 663-670. 
7 Vasilyev, A.V., \& Vasilyev, V.B. (2017). On a digital approximation for pseudo-differential operators. Proc. Appl. Math. Mech., Vol. 17, Issue 1, 763-764.

8 Gradshteyn, I.S., \& Ryzhik, I.M. (2007). Tables of integrals, series, and products. New York: Academic Press.

9 Vasilyev, V.B. (2016). Discrete equations and periodic wave factorization. AIP Conf. Proc., Vol. 1759, 0200126-1-5.

10 Vasilyev, V.B. (2017). The periodic Cauchy kernel, the periodic Bochner kernel, and discrete pseudodifferential operators. AIP Conf. Proc., Vol. 1863, 140014-1-4.

11 Vasilyev, V.B. (2018). Discrete pseudo-differential operators and boundary value problems in a half-space and a cone. Lobachevskii J. Math., Vol. 39, No. 2, 289-296.

В.Б. Васильев

\section{Арнайы псевдодифференциалды теңдеулер үшін кейбір жуықтау есептеулер}

Мақалада дискретті псевдодифференциалды операторлар мен теңдеулерді олардың үздіксіз аналогтары үшін жуықтау операторлар мен теңдеулер ретінде қарастырылды. Осы мақсатпен мұндай теңдеулердің шешімділігіне сәйкес дискретті кеңістіктер зерттелді, дискретті және үздіксіз шешімдердің қателіктерін бағаланды. Бұл тәсіл Евклид кеңістігінің белгілі бір қарапайым облыстарында дискретті Фурье түрлендіруі және факторизациялау әдісіне негізделген.

Kiлm сөздер: дискретті псевдодифференциалды оператор, периодты факторизация, шешімділік, жуықтау шешімі, қателерді бағалау.

В.Б. Васильев

\section{О некоторых приближенных вычислениях для специальных псевдодифференциальных уравнений}

В статье рассмотрены дискретные псевдодифференциальные операторы и уравнения как приближенные операторы и уравнения для их непрерывных аналогов. Изучена разрешимость таких уравнений в соответствующих дискретных пространствах, и даны некоторые оценки погрешности для дискретных и непрерывных решений. Этот подход основан на дискретном преобразовании Фурье и технике факторизации, которая используется для специальных канонических областей в евклидовом пространстве.

Ключевые слова: дискретный псевдодифференциальный оператор, периодическая факторизация, разрешимость, приближенное решение, оценки погрешности. 